\title{
Exchange Reactions of trans-1,2-Diaminocyclohexane- tetraacetate Complexes of Magnesium, Calcium, Strontium, and Lanthanum Ions in Aqueous Alkaline Solution
}

\author{
NIELS RHOD LARSEN and ARNE JENSEN
}

The Royal Danish School of Pharmacy, Chemical Laboratory A, DK-2100 Copenhagen $\emptyset$, Denmark

The rate of transfer of magnesium, calcium, strontium, and lanthanum ions from $\mathrm{D}-(-)$ trans-1,2-diaminocyclohexane- $N, N, N^{\prime}, N^{\prime}$-tetraacetate $\equiv$ D-CDTA - to D,L-CDTA ${ }^{4-}$ has been studied in alkaline solution. The rate of reaction is independent of the HCDTA ${ }^{3-}$ and CDTA $^{4-}$ concentrations for all the ions studied with the exception of the lanthanum ion for which a first order dependence on the CDTA ${ }^{4-}$ concentration is observed. The $\left[\mathrm{H}^{+}\right]$profile of the rate constants of the dissociation reactions has been determined and a mechanism consistent with the observed $\left[\mathrm{H}^{+}\right]$profile is given. This mechanism is valid for the CDTA complexes of both the alkaline earth ions and the lanthanum ion. The activation parameters for the resolved rate constants have also been determined and support the stated mechanism.

The kinetics of the dissociation of the alkaline earth ion complexes of trans-1,2-diaminocyclohexane- $N, N, N^{\prime}, N^{\prime}$-tetraacetate (CDTA) have in a previous paper ${ }^{1}$ been shown to be dependent on $\left[\mathrm{H}^{+}\right]$in a complex way. Glentworth et al.,2 Brücher and Szarvas, ${ }^{3}$ and Nyssen and Margerum ${ }^{4}$ have studied the kinetics of the dissociation of the lanthanide ion complexes of CDTA in neutral or acidic solution. Glentworth et al. and Nyssen and Margerum have shown that the $\left[\mathrm{H}^{+}\right]$independent term in the rate law for the dissociation is too large to be equal to the direct dissociation of the complexes to $\mathrm{Ln}^{3+}$ and CDTA $^{4-}$; however, the mechanisms proposed for the reaction path independent of $\left[\mathrm{H}^{+}\right]$are not in agreement (cf. Ref. 2b).

The present studies deal with the kinetics of dissociation at hydrogen ion concentrations where the usual first order dependence on $\left[\mathrm{H}^{+}\right]$ is not observed. The dissociation refers to the reaction scheme in (1).

$\operatorname{MCDTA} \underset{\mathrm{H}^{+}}{\stackrel{k_{\mathrm{d}}}{\longrightarrow}} \mathrm{M}+\mathrm{CDTA}$

The $\left[\mathrm{H}^{+}\right]$range has been expanded and studies on the dissociation of LaCDTA have been included ( $c f$. Ref. 1). The mechanism of dissociation of MCDTA at low $\left[\mathrm{H}^{+}\right]$is found to be similar for $\mathbf{M}=\mathrm{Mg}, \mathrm{Ca}, \mathrm{Sr}$, or La. The stated mechanism agrees with that suggested by Nyssen and Margerum ${ }^{4}$ for the dissociation of the lanthanide complexes of CDTA.

The overall reactions studied are shown in (2a) ( $\mathrm{M}=\mathrm{Mg}, \mathrm{Ca}, \mathrm{Sr}$ or $\mathrm{La})$ and (2b). Reaction (2b) has been included in the investigation since a pronounced dependence on [CDTA ${ }^{4-}$ ] exists for La(D-CDTA) in reaction (2a). The charges, protons, and nomenclature for the optical rota-

$\mathrm{M}(\mathrm{D}-\mathrm{CDTA})+\mathrm{D}, \mathrm{I}-\mathrm{CD}$ TA $\rightarrow \mathrm{M}(\mathrm{D}, \mathrm{L}-\mathrm{CDTA})+$ D-CDTA

$\mathrm{La}(\mathrm{D}-\mathrm{CDTA})+\mathrm{Sr}(\mathrm{D}, \mathrm{L}-\mathrm{CDTA}) \rightarrow \mathrm{La}(\mathrm{D}, \mathrm{L}-\mathrm{CDTA})$

+ Sr(D-CDTA)

tion have been omitted for clarity in (2a) and (2b). Each one of the enantiomers L-CDTA and D-CDTA forms only one of the two possible isomeric complexes due to the stereospecificity of this ligand. ${ }^{5,6}$

\section{EXPERIMENTAL}

Chemicals. D, $\mathrm{L}_{-} \mathrm{H}_{4} \mathrm{CDTA}$, the racemic form of trans-1,2-diaminocyclohexane- $N, N, N^{\prime}, N^{\prime}$-tetraacetic acid (Fluka p.a.) was recrystallized by

Acta Chem. Scand. A 28 (1974) No. 6 
dissolving in dilute $\mathrm{NaOH}$ followed by the addition of $\mathrm{HNO}_{3}$. D-H $\mathrm{CDTA}\left(\mathrm{D}(-) \mathrm{H}_{4} \mathrm{CDTA}\right)$ was contributed by Professor K. H. Pearson, Cleve. land State University, Cleveland, Ohio, U.S.A., and was used without further purification. The metal salts used were the nitrates of analytical grade. $\mathrm{D}, \mathrm{L}-\mathrm{H}_{4} \mathrm{CDTA}$ and nitrates of $\mathrm{Mg}, \mathrm{Ca}, \mathrm{Sr}$, and La were quantitatively analyzed by complexometric titrations.

Weighed amounts of the metal nitrate and $\mathrm{H}_{4}$ CDTA were dissolved to give the desired concentrations of the reactants. 2,6-Lutidin, tris(hydroxymethyl)methylamine, borate, and $N$-ethylpiperidine of the highest available purity were used and the solutions were adjusted to the desired $\mathrm{pH}$ by adding a solution of $\mathrm{CsOH}$ to the acidic form of these bases. $\mathrm{CsOH}$ was prepared by ion exchange of $\mathrm{CsNO}_{3}$ on an IRA 400 resin (BDH). $\left[\mathrm{CO}_{3}{ }^{2-}\right]$ constituted less than $1 \%$ of $\left[\mathrm{OH}^{-}\right]$in the $\mathrm{CsOH}$ solutions, as determined by titration with acid. The ionic strength was adjusted using $\mathrm{CsNO}_{3}$ instead of nitrates of $\mathrm{Li}^{+}$, $\mathrm{Na}^{+}$or $\mathrm{K}^{+}$as it has been shown that complexes are formed between these metal ions and CDTA, whereas $\mathrm{Cs}^{+}$has not been observed to form CDTA complexes in the $\mathrm{pH}$ ranges used. ${ }^{7,8}$

Apparatus. A Perkin.Elmer Model 141 photoelectric polarimeter (with potentiometric readout) in combination with a "Servograph REC 51" recorder equipped with a high sensitivity unit "REA 112" (Radiometer, Copenhagen) was used to monitor the change in optical rotation as a function of time during the reactions. The polarimeter had the following five wavelengths available: $589,578,546,436$, and $365 \mathrm{~nm}$. However, in this work, $365 \mathrm{~nm}$ was used exclusively because of the greater change in optical rotation at this wavelength during reaction (2). The $1 \mathrm{dm}$ polarimeter cell with quartz windows was thermostated to a precision of $\pm 0.1^{\circ} \mathrm{C}$. The "rapid" reactions were followed by means of a simple mixing device consisting of a $\mathrm{Y}$-formed glass tube which was connected to two calibrated glass syringes containing the reactants. A water bath of the desired temperature was used to thermostate the glass syringes and the $\mathbf{Y}$-formed glass tube. The mixing of the reactants was completed within $5 \mathrm{~s}$, and the response time of the polarimeter and recorder was about $10 \mathrm{~s}$ following the initial mixing.

The $\mathrm{pH}$ of the reaction mixture was measured after the completion of the reaction with a " $\mathrm{pH}$ Meter 4" equipped with a calomel electrode, $\mathrm{K}$ 401, and a glass electrode, G 202 B (Radiometer, Copenhagen).

Rate measurements. The $\mathrm{pH}$ ranges used in the study of reaction (2) are shown in Figs. 2, 3, 4, and 6. Titrations of the complexes to be discussed have shown that protonated forms as well as the hydroxo forms of these complexes are found in negligible concentrations in the $\mathrm{pH}$ ranges studied (cf. Ref. 1). The formula for the investigated CDTA complexes is therefore MCDTA $^{(4-n)}$ - where $n$ is the charge of the metal ion.
Table 1. Molar rotations (deg. $\mathrm{M}^{-1} \mathrm{~cm}^{-1}$ ) of D-CDTA and the D-CDTA complexes investigated. $^{a}$

\section{CDTA MgCDTA CaCDTA SrCDTA LaCDTA}

\begin{tabular}{lllll}
-5.4 & 5.3 & 2.5 & 1.3 & 8.7 \\
\hline
\end{tabular}

${ }^{a} \mathrm{pH} \quad 10.0 ; N$-ethylpiperidine buffer $5 \times 10^{-3} \mathrm{M}$; $25^{\circ} \mathrm{C} ; 365 \mathrm{~nm}$.

Table 1 shows the values of the molar rotations of the optically active species employed in reaction (2). The molar rotations are calculated from measurements performed on $10^{-3} \mathrm{M}$ solutions with $\mathrm{pH}$ adjusted to 10.0 with $\mathrm{CsOH}$. The total change in rotation during reaction (2) is $0.07-0.11^{\circ}$ for the concentrations used. Different initial concentrations of the decomposing species were used; in each case a tenfold to fiftyfold excess of entering ligand was present, which was found to be sufficient to make the overall reaction to go to completion.

As opposed to the exchange reactions with $\mathrm{Cu}(\mathrm{II})$ ion in $\mathrm{NH}_{4}{ }^{+} / \mathrm{NH}_{3}$ solutions, ${ }^{1}$ changes in $\left[\mathrm{H}^{+}\right]$do not occur for reaction (2). Buffer concentrations of $5 \times 10^{-8} \mathrm{M}$ are therefore sufficient for maintaining the desired $\mathrm{pH}$ in the present investigation. For $M=L a$ in reaction (2a) at low $\mathrm{pH}$, no buffer is required since the excess of CDTA supplies the solution with a buffer capacity in this $\mathrm{pH}$ range. In some kinetic runs, it is possible to maintain a given $\mathrm{pH}$ with different buffers, all of which yield identical rate constants; i.e., no buffer effect is observed. The hydrogen ion concentration is calculated as log $\left[\mathrm{H}^{+}\right]=-\mathrm{pH}$; that is, the activity coefficient which is a constant at the ionic strength maintained here has been omitted.

A least squares analysis performed on a "Wang" desk computer was used to obtain the best linear dependence.

The stability constants used in the present work are given in Table 2.

Table 2. Stability constants.

Complex $\log K\left(\mathbf{M}^{-1}\right)$

\begin{tabular}{ll}
\hline H2CDTA & $(6.1)^{a}$ \\
HCDTA & $(13.2)^{b}$ \\
MgCDTA & $(11.0)^{a}$ \\
CaCDTA & $(13.1)^{a}$ \\
SrCDTA & $(10.5)^{a}$ \\
LaCDTA & $(16.9)^{a}$ \\
\hline
\end{tabular}

$a^{a}$ Ref. $10 ; \mu=0.1\left(\mathrm{KNO}_{3}\right)$; corrected to $25^{\circ} \mathrm{C}$ by the thermodynamic values from Ref. $10{ }^{b}$ Ref. 7; $\mu=0.1\left(\mathrm{CsNO}_{3}\right) ; 25^{\circ} \mathrm{C}$. 


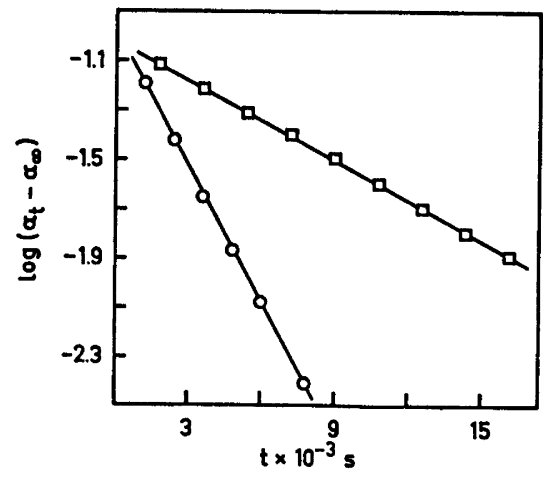

Fig. 1. First order plots. O reaction (2a); $[\mathrm{Mg}(\mathrm{D}-\mathrm{CDTA})]_{0}=1.0 \times 10^{-8} \mathrm{M} ;[\mathrm{D}, \mathrm{L}-\mathrm{CDTA}]_{0}=$ $5.0 \times 10^{-2} \mathrm{M} ; \mathrm{pH} 8.29 ; 25.0^{\circ} \mathrm{C} ; \mu=0.5$. $\square$ reaction (2b); [La(D.CDTA) $]_{0}=1.0 \times 10^{-3} \mathrm{M} ;[\mathrm{Sr}(\mathrm{D}, \mathrm{L}$ CDTA $)]_{0}=1.0 \times 10^{-2} \mathrm{M} ; \mathrm{pH} 9.38 ; 25.0^{\circ} \mathrm{C} ; \mu=0.1$.

The exchange reactions studied are all carried out under conditions which make them pseudo first order. Two first order plots representing, respectively, reactions (2a) and (2b) are shown in Fig. 1. [] $]_{0}$ indicates initial concentration.

\section{RESULTS}

Magnesium, calcium, strontium. The kinetics of dissociation for the CDTA complexes according to reaction (2a) have been examined as a function of hydrogen ion concentration as well as temperature.

The results are shown in Figs. 2, 3, and 4 where $k_{\mathrm{d}}$ is the observed first order rate constant. The $\log k_{\mathrm{d}}$ versus $\mathrm{pH}$ plot is chosen in order to be able to include all the experimental results for the dissociation reactions of a given complex in one figure. Log $k_{\mathrm{d}}$ shows a linear dependence on $\mathrm{pH}$ at low values of $\mathrm{pH}$ with a slope of approximately -1 thereby indicating that a first order dependence on hydrogen ion concentration dominates in this $\mathrm{pH}$ range. Furthermore, zero order dependence on $\left[D, L_{-}-\right.$ HCDTA $\left.^{8-}\right]$ or [D,L-CDTA $\left.{ }^{4-}\right]$ is observed as illustrated from the experiments with different concentrations of D,I-CDTA. $k_{\mathrm{d}}$ is accordingly the rate constant of the dissociation reaction, $k_{\mathrm{d}}$ being a function only of $\left[\mathrm{H}^{+}\right]$and the medium.

Figs. 2, 3, and 4 give, on the other hand, no distinct information on the $\left[\mathrm{H}^{+}\right]$profile at high values of $\mathrm{pH}$. Plots of $k_{\mathrm{d}}$ versus $\left[\mathrm{H}^{+}\right]$for high
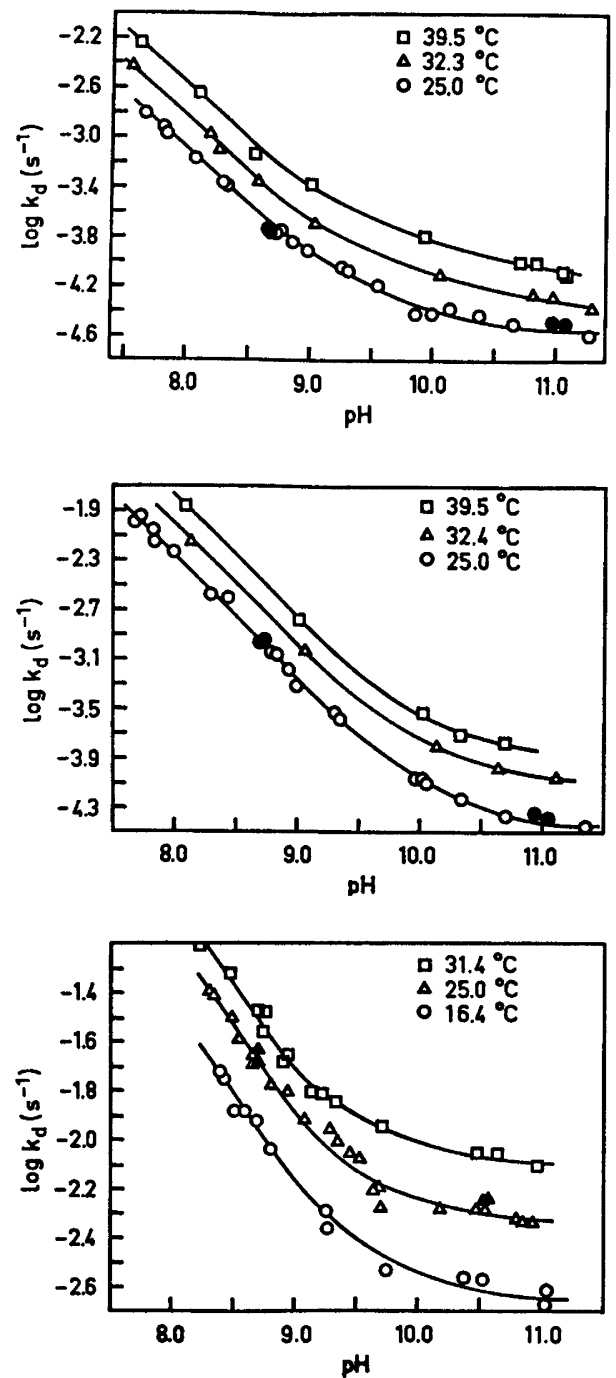

Figs. 2-4. $\log k_{\mathrm{d}}$ versus $\mathrm{pH}$ for $\mathrm{M}=\mathrm{Mg}, \mathrm{Ca}$, and $\mathrm{Sr}$, respectively. [M(D-CDTA) $]_{0}=1.0 \times 10^{-3} \mathrm{M}$; $[\mathrm{D}, \mathrm{L}-\mathrm{CDTA}]_{0}=5.0 \times 10^{-2} \mathrm{M}$. The symbols, and $\Delta$, indicate $\left[\mathrm{D}, \mathrm{L}_{-}-\mathrm{CDTA}\right]_{0}=1.0 \times 10^{-2} \mathrm{M} ; 25.0$ ${ }^{\circ} \mathrm{C} . \mu=0.5$.

values of $\mathrm{pH}$ (cf. Fig. 5) yield profiles similar to those found in Ref. 1.

The straight lines in Fig. 5 display the results of a linear regression analysis of $k_{\mathrm{d}}$ versus $\left[\mathrm{H}^{+}\right]$ at higher $\left[\mathrm{H}^{+}\right](c f$. the following section, "Discussion").

Lanthanum. The observed first order rate constants for reaction (2a) ( $M=L a)$ and (2b) are designated $k_{\mathrm{c}}$ and $k_{\mathrm{s}}$, respectively. The deter-

Acta Chem. Scand. A 28 (1974) No. 6 


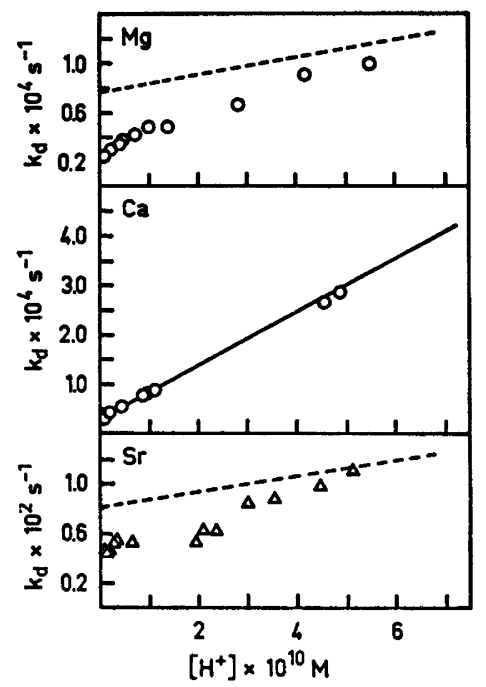

Fig. 5. Dependence of $k_{\mathrm{d}}$ on $\left[\mathrm{H}^{+}\right]$for $\mathrm{pH}$ 9.2-11.4 for $\mathrm{M}=\mathrm{Mg}, \mathrm{Ca}$, and $\mathrm{Sr}$ respectively; $25.0^{\circ} \mathrm{C} ; \mu=0.5$.

mination of $k_{\mathrm{s}}$ from the double exchange in reaction (2b) is feasible only if $k_{\mathrm{d}}$ for the dissociation of SrCDTA is much larger than $k_{\mathrm{s}}$. Otherwise, $k_{s}$ will necessarily be dependent on the rate of dissociation of the scavenger, SrCDTA. From Figs. 4 and 6 it is seen that $k_{\mathrm{d}}$ for SrCDTA is indeed much larger than $k_{\mathrm{s}}$. Reaction (2b) will proceed to completion only if [D,L-CDTA] is considerably higher than [DCDTA]. This condition is fulfilled when using an excess of $\operatorname{Sr}(D, L-C D T A)$ since the ratio between the stability constants for SrCDTA and

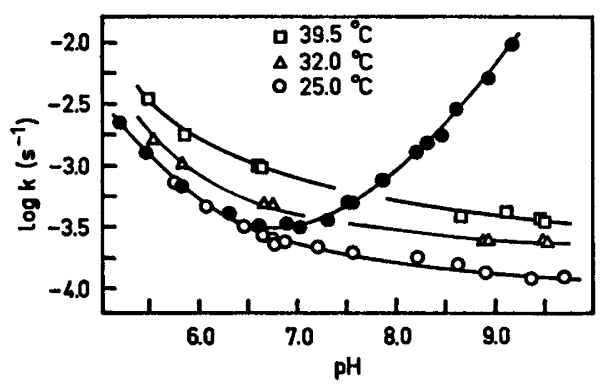

Fig. 6. $\log k_{\mathrm{s}}$ and $\log k_{\mathrm{c}}$ versus $\mathrm{pH}$ for $\mathrm{M}=$ La. The symbols $\square \triangle O$ are used for $k_{\mathrm{s}}$; [La(DCDTA $)]_{0}=1.0 \times 10^{-3} \mathrm{M} ;[\operatorname{Sr}(\mathrm{D}, \mathrm{L}-\mathrm{CDTA})]_{0}=1.0 \times$ $10^{-2} \mathrm{M}$. The symbol $\bigcirc$ is used for $k_{\mathrm{c}}$; $[\mathrm{La}(\mathrm{D}$. CDTA $]_{0}=5.0 \times 10^{-4} \mathrm{M} ; \quad\left[D, I_{-}-C D T A\right]_{0}=1.0 \times$ $10^{-2} \mathrm{M} ; 25.0^{\circ} \mathrm{C} . \mu=0.1$.

Acta Chem. Scand. A 28 (1974) No. 6
LaCDTA are of the correct order of magnitude (cf. Table 2).

From Fig. 6 it is seen that for LaCDTA the reactions approach first order in $\left[\mathrm{H}^{+}\right]$at low values of $\mathrm{pH}$ and that the exchange reaction of the ligand is faster than the double exchange reaction with SrCDTA at $\mathrm{pH}>6.5$. The plot of log $k_{\mathrm{c}}$ versus $\mathrm{pH}$ in Fig. 6 indicates that $k_{\mathrm{c}}$ depends specifically on [D,L-CDTA $\left.{ }^{4-}\right]$ and is independent of [D,L-HCDTA $\left.{ }^{3-}\right]$ and [D,L- $\left.-\mathrm{H}_{2} \mathrm{CDTA}^{2-}\right]$. That $k_{\mathrm{c}}$ has this particular form for dependence is evident from the fact that $k_{\mathrm{c}}$ is equal to $k_{\mathrm{s}}$ for $\mathrm{pH}<6.5$ and from the fact that $k_{\mathrm{s}}$, for steric reasons, must be independent of [SrCDTA] (cf. Margerum $\left.{ }^{\circ}\right)$. Furthermore, $k_{\mathrm{c}}$ and $k_{\mathrm{s}}$ must be equal to $k_{\mathrm{d}}$ for $\mathrm{pH}<6.5, k_{\mathrm{d}}$ being the rate constant of dissociation analogous to the similar rate constant of dissociation of the alkaline earth complexes. $k_{\mathrm{d}}$ is included in both $k_{\mathrm{c}}$ and $k_{\mathrm{s}}$, the concentration of $\mathrm{D}, \mathrm{L}_{-}-\mathrm{CDTA}^{4-}$ being negligible in the experiments with the double exchange of SrCDTA as compared with the experiments with the ligand exchange ( $c f$. the magnitude of the stability constant of SrCDTA in Table 2). Furthermore, the exchange reaction between La(D-CDTA) and D-CDTA ${ }^{4-}$ does not give rise to a change in rotation which means that the exchange reaction between La(D-CDTA) and $\mathrm{L}_{\text {-CDTA }}{ }^{4}$ - is the only one being observed.

The difference between $k_{\mathrm{c}}$ and $k_{\mathrm{s}}$ is calculated according to eqn. (3). $k_{\text {CDTA }}$ LaCDTA is the rate constant of the reaction between La(D.CDTA) and $L_{-}-C^{-} A^{4-}$ where $c$ indicates [L-CDTA $\left.{ }^{4-}\right]$ in the ligand exchange.

$$
k_{\mathrm{c}}-k_{\mathrm{s}}=k_{\mathrm{CDTA}}{ }^{\mathrm{LaCDTA}}\left[\mathrm{L}_{1}-\mathrm{CDTA}^{4-}\right]_{\mathrm{c}}
$$

$\left[\mathrm{L}-\mathrm{HCDTA}^{3-}\right]_{\mathrm{c}}$ can, in the $\mathrm{pH}$ range $7.5-9.2$, be set equal to the total concentration of free I.CDTA (cf. Table 2); i.e., [L-HCDTA $\left.{ }^{3-}\right]_{c}$ is half the free ligand concentration. $k_{\mathrm{c}}-k_{\mathrm{s}}$ may then be stated as in eqn. (4).

$k_{\mathrm{c}}-k_{\mathrm{s}}=k_{\mathrm{CDTA}}{ }_{\mathrm{LaCDTA}} \frac{\left[\mathrm{L}_{-}-\mathrm{HCDTA}^{3-}\right]_{\mathrm{c}}}{K_{\mathrm{HCDTA}}\left[\mathrm{H}^{+}\right]}$

Fig. 7 shows a plot of $k_{\mathrm{c}}-k_{\mathrm{s}}$ versus $\left[\mathrm{H}^{+}\right]^{-1}$ where the slope of the straight line obtained is used for the calculation of $k_{\mathrm{CDTA}}{ }^{\mathrm{LaCDTA}}$. For the calculation of $k_{\mathrm{c}}-k_{\mathrm{s}}$ the observed values of $k_{\mathrm{c}}$ are used whereas an estimated value for $k_{\mathrm{s}}$ at the same $\left[\mathrm{H}^{+}\right]$as $k_{\mathrm{c}}$ is obtained by interpolation between the observed values of $k_{\mathrm{s}}$. The vanish. 


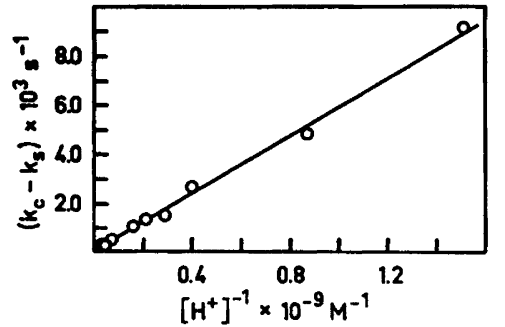

Fig. 7. $k_{\mathrm{c}}-k_{\mathrm{s}}$ versus $\left[\mathrm{H}^{+}\right]^{-1}$ for the calculation of $k_{\mathrm{CDTA}}{ }^{\mathrm{LaCDTA}} ; 25.0^{\circ} \mathrm{C} ; \mu=0.1$.

ing intercept for the straight line in Fig. 7 corroborates eqn. (4). The low $\left[\mathrm{Sr}^{2+}\right.$ ] in connection with reaction (2b) does not result in a contribution to $k_{\mathrm{s}}$ since a dependence of $k_{\mathrm{s}}$ on $\left[\mathrm{Sr}^{2+}\right]$ would give rise to a negative intercept and non-linearity in Fig. 7. $k_{\text {CDTA }}$ LaCDTA is calculated from the slope to be $1.9 \times 10^{4} \mathrm{M}^{-1} \mathrm{~s}^{-1}$ when using $K_{\mathrm{HCDTA}}=10^{13.2} \mathrm{M}^{-1} \quad(c f$. Table 2) and $\left[\mathrm{L}-\mathrm{HCDTA}^{\mathrm{s}-}\right]_{\mathrm{c}}=5.0 \times 10^{-8} \mathrm{M}$. The value of $k_{\text {CDTA }}$ IaCDTA is surprisingly large compared with the rate constant of the reaction between $\mathrm{Pb}\left(\mathrm{L}_{-}-\mathrm{CDTA}\right)$ and D-CDTA 4 - which according to Carr and Baker ${ }^{8}$ is equal to $3.77 \times 10^{-2} \mathrm{M}^{-1} \mathrm{~s}^{-1}$. Otherwise, the work done by these authors and that done in the present study agree inasmuch as no dependence on [HCDTA ${ }^{2-}$ ] is observed. The observed rate of both the ligand and double exchange reaction is expressed by eqn. (5) where the bracket is equal to the observed first order rate constants $k_{\mathrm{c}}$ or $k_{\mathrm{s}}$.

$$
\begin{aligned}
& -\frac{\mathrm{d}[\mathrm{LaCDTA}]}{\mathrm{d} t}= \\
& \left\{k_{\mathrm{CDTA}}{ }^{\mathrm{LaCDTA}}\left[\mathrm{L}_{-}-\mathrm{CDTA}^{4-}\right]+k_{\mathrm{d}}\right\}[\text { LaCDTA }]
\end{aligned}
$$

[L.CDTA ${ }^{4-}$ ] in the double exchange, indicated by $\mathrm{s}$, is calculated from eqn. (6) which is valid in the $\mathrm{pH}$ range $7.5-9.7$.

$$
\left[\mathrm{L}_{-}-\mathrm{CDTA}^{4-}\right]_{\mathrm{s}}=\left(\frac{\left[\mathrm{Sr}\left(\mathrm{L}_{-}-\mathrm{CDTA}\right)\right]}{K_{\mathrm{SrCDTA}} K_{\mathrm{HCDTA}}\left[\mathrm{H}^{+}\right]}\right)^{\frac{1}{2}}
$$

The rate constant $k_{\mathrm{d}}$ for the dissociation of LaCDTA is calculated from $k_{\mathrm{s}}$ using eqns. (5) and (6) (cf. Table 3).

Table 3 shows $k_{\mathrm{d}}$ as being negative at $\mathrm{pH}$ 9.71. This inconsistency may be attributed to the fact that the value of the stability constant for SrCDTA $\left(10^{10.5} \mathrm{M}^{-1}\right)$ is too low. This value has been determined with $\mathbf{K}^{+}$present. The presence of $\mathrm{K}^{+}$causes an error since this ion is known to coordinate with CDTA (cf. Ref. 7). It can, however, be stated with certainty that $k_{\mathrm{d}}$ extrapolated to $\left[\mathrm{H}^{+}\right]=0$ is negligible. Qualitatively both $k_{\mathrm{s}}$ and $k_{\mathrm{d}}$ have the same depend. ence on $\left[\mathrm{H}^{+}\right]$as that of $k_{\mathrm{d}}$ in the dissociation reaction of the alkaline earth complexes. Furthermore, $k_{\mathrm{s}}$ is equal to $k_{\mathrm{d}}$ at $\mathrm{pH}<7.5$.

\section{DISCUSSION}

Fig. 8 shows qualitatively the dependence of $k_{\mathrm{d}}$ on $\left[\mathrm{H}^{+}\right]$for MCDTA in the $\mathrm{pH}$ range investigated $(\mathbf{M}=\mathbf{M g}, \mathbf{S r}$ or $\mathrm{La})$. A similar $\left[\mathrm{H}^{+}\right]$ profile of $k_{\mathrm{d}}$ for BaCDTA has also been found (cf. Jensen and Larsen ${ }^{1}$ ). The $\left[\mathrm{H}^{+}\right]$profile of $k_{\mathrm{d}}$ for CaCDTA is, on the other hand, found to be a straight line. The mechanism of the dissociation reaction for CaCDTA is, however, assumed to be the same as that for the dissociation reactions of the other alkaline earth and lanthanum complexes. This assumption is main-

Table 3. Calculation of $k_{\mathrm{d}}$ for $\mathrm{M}=\mathrm{La}$ in the $\mathrm{pH}$ range $7.5-9.7 .^{a}$

\begin{tabular}{llll}
\hline $\mathrm{pH}$ & $\begin{array}{l}k_{\mathrm{s}} \times 10^{4} \\
\mathrm{~s}^{-1}\end{array}$ & $\begin{array}{l}k_{\mathrm{CDTA}} \\
\mathrm{s}^{-1 b}\end{array}$ & $\begin{array}{c}k_{\mathrm{d}} \times 10^{4} \\
\mathrm{~s}^{-1}\end{array}$ \\
\hline 7.56 & 1.92 & 0.11 & 1.81 \\
8.21 & 1.75 & 0.24 & 1.51 \\
8.62 & 1.56 & 0.38 & 0.18 \\
8.91 & 1.33 & 0.53 & 0.26 \\
9.38 & 1.17 & 0.91 & $(-0.11)$ \\
\hline 9.71 & 1.22 & 1.33 & \\
\hline
\end{tabular}

\footnotetext{
a $25.0^{\circ} \mathrm{C} ; \mu=0.1 .^{b}\left[\mathrm{~L}_{\mathrm{L}} \mathrm{CDTA}^{4-}\right]_{0}$ is calculated from eqn. (6); $[\mathrm{Sr}(\mathrm{L}-\mathrm{CDTA})]_{0}=5.0 \times 10^{-3} \mathrm{M} ; K_{\mathrm{SrCDTA}}$ and $K_{\text {HCDTA }}$ from Table 2 .
} 


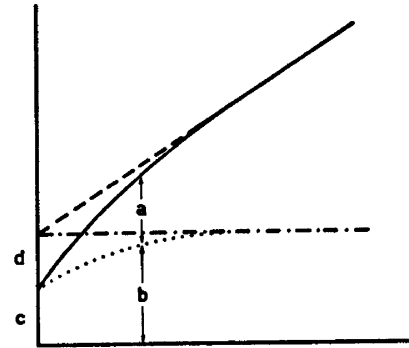

Fig. 8. Typical form of the curve of $k_{\mathrm{d}}$ versus $\left[\mathrm{H}^{+}\right]$; for $\mathrm{M}=\mathrm{Ca}$ see text. $\mathrm{a}=k_{\mathrm{H}} \mathrm{MCDTA}^{\mathrm{M}}\left[\mathrm{H}^{+}\right] ; \mathrm{b}=$ $k_{\mathrm{d}}-k_{\mathrm{H}}{ }^{\mathrm{MCDTA}}\left[\mathrm{H}^{+}\right] ; \quad \mathrm{c}=k_{1}{ }^{\mathrm{MCDTA}} ; \quad \mathrm{d}=k_{2}$ MCDTA; $^{\text {MCD }}$ $k^{\mathrm{MCDTA}}=k_{1}{ }^{\mathrm{MCDTA}}+k_{2}{ }^{\mathrm{MCDTA}}$. The solid curve is the observed $k_{\mathrm{d}} \cdot k_{-}-$is the extrapolated straight line for the observed first order $\left[\mathrm{H}^{+}\right]$ dependence at low values of $\mathrm{pH}$. ... is the $\left[\mathrm{H}^{+}\right]$profile for the reaction rate according to the proposed mechanism in (8). - - - - - shows how this mechanism is independent of $\left[\mathrm{H}^{+}\right]$for $\left[\mathrm{H}^{+}\right]$greater than a given value corresponding to the straight line for $k_{\mathrm{d}}$.

ly based upon the magnitude of the activation parameters.

Fig. 8 shows both that $k_{\mathrm{d}}$ is given by eqn. (7) at low values of $\mathrm{pH}$, and that this equation is invalid at higher $\mathrm{pH}$ values; at high $\mathrm{pH}$ the difference between $k_{\mathrm{d}}$ and $k_{\mathrm{H}}{ }^{\mathrm{MCDTA}}\left[\mathrm{H}^{+}\right]$is

$k_{\mathrm{d}}=k^{\mathrm{MCDTA}}+k_{\mathrm{H}} \mathrm{MCDTA}^{\mathrm{M}}\left[\mathrm{H}^{+}\right]$

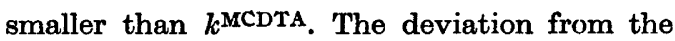
straight line in Fig. 8 is explained by the mechanism depicted in scheme (8) where the rate determining step is $1 \rightarrow 2$. Mechanism (8) gives the direct dissociation of $\operatorname{MCDTA}^{(4-n)-}$

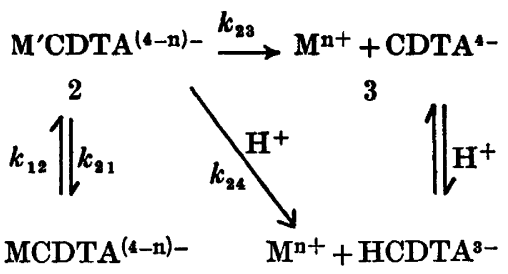

1

4

along the paths $1 \rightarrow \mathbf{2} \rightarrow \mathbf{3}$. Furthermore, this mechanism also explains the $k^{\text {MCDTA }}$ part of $k_{\mathrm{d}}$ (i.e., paths $1 \rightarrow 2 \rightarrow 3$ and $1 \rightarrow 2 \rightarrow 4$ ) and, as regards this aspect, is in accordance with the mechanism assumed by Nyssen and Margerum. ${ }^{4}$

Jensen and Larsen ${ }^{1}$ concluded that $k_{\mathrm{H}}{ }^{\text {MCDTA }}$ is $\left[\mathrm{H}^{+}\right]$dependent and accordingly interpreted $k^{\mathrm{MCDTA}}$ as the rate constant for the direct dissociation of the CDTA complexes. Both $k_{\mathrm{H}}$ MCDTA and $k^{\mathrm{MCDTA}}$ are assumed to be $\left[\mathrm{H}^{+}\right]$independent in the present investigation.

The difference between $k_{\mathrm{d}}$ and $k_{\mathrm{H}}{ }^{\mathrm{MCDTA}}\left[\mathrm{H}^{+}\right]$ may be expressed as in eqn. (9) when applying the "Steady State" approximation to species 2 in mechanism (8).

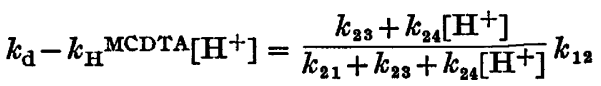

Basolo and Pearson ${ }^{11}$ have treated complexes of the chelate type in an analogous fashion and have arrived at a mechanism similar to (8).

The dependence of the reaction rate on $\left[\mathrm{H}^{+}\right]$ is, according to mechanism (8), determined by the magnitude of $k_{21}$ relative to $k_{24}\left[\mathrm{H}^{+}\right]$. Eqn. (9) is reduced to eqn. (10) if $k_{21}$ is negligible compared with $k_{24}\left[\mathrm{H}^{+}\right]$. Eqn. (7) shows that in this case $k_{12}$ is identical to $k^{\text {MCDTA }}$.

$\left.k_{\mathrm{d}}-k_{\mathrm{H}} \mathrm{MCDTA}^{\mathrm{M}} \mathrm{H}^{+}\right]=k_{12}=k^{\mathrm{MCDTA}}$

Eqn. (9) is, on the other hand, reduced to eqn. (11) if $k_{24}\left[\mathrm{H}^{+}\right]$is negligible as compared to $k_{21}$.

$k_{\mathrm{d}}-k_{\mathrm{H}} \operatorname{MCDTA}\left[\mathrm{H}^{+}\right]=\frac{k_{23}+k_{24}\left[\mathrm{H}^{+}\right]}{k_{21}+k_{23}} k_{12}$

If $\left[\mathrm{H}^{+}\right]$is small, a first order dependence on the hydrogen ion concentration is to be expected. Upon extrapolating to the $k_{\mathrm{d}}$-axis in the plot of $k_{\mathrm{d}}$ versus $\left[\mathrm{H}^{+}\right]$(cf. Fig. 8), it is seen that $k_{\mathrm{d}}$ can be expressed as in eqn. (12).

$k_{\mathrm{d}}=\frac{k_{23} k_{12}}{k_{21}+k_{23}} \equiv k_{1}{ }^{\mathrm{MCDTA}}$

It is furthermore seen from this figure that $k^{\mathrm{MCDTA}}=k_{1} \mathrm{MCDTA}^{\mathrm{MC}}+k_{2} \mathrm{MCDTA}$.

$k_{\mathrm{H}}{ }^{\mathrm{MCDTA}}, k^{\mathrm{MCDTA}}, k_{1}{ }^{\mathrm{MCDTA}}$, and $k_{2}{ }^{\mathrm{MCDTA}}$ are thus determined from the experimental results. $k_{\mathrm{H}}{ }^{\mathrm{MCDTA}}$ and $k^{\mathrm{MCDTA}}$ are - as shown in previous sections - the slope and the intercept, respectively, of the straight line found at low values of $\mathrm{pH}$ when plotting $k_{\mathrm{d}}$ versus $\left[\mathrm{H}^{+}\right] . k_{1}{ }^{\mathrm{MCDTA}}$ is the intercept of the straight line obtained when plotting $k_{\mathrm{d}}$ versus $\left[\mathrm{H}^{+}\right]$, but only at high values of pH. $k_{2}{ }^{\text {MCDTA }}$ is calculated as described in the preceding paragraph. It has to be emphasized, however, that $\left[\mathrm{H}^{+}\right]$must be one to two orders of magnitude greater when determining $k^{\text {MCDTA }}$ than when determining $k_{1}$ MCDTA. This condition arises as a consequence of the approximations leading to eqns. (10) and (12). 
Table 4. The resolved rate constans for the dissociation of MCDTA complexes. ${ }^{a}$

\begin{tabular}{|c|c|c|c|c|c|c|c|}
\hline $\mathbf{M}$ & $\stackrel{t}{{ }^{t} \mathrm{C}}$ & $\begin{array}{l}k^{\mathrm{MCDTA}} \\
\mathbf{s}^{-1}\end{array}$ & $\begin{array}{l}k_{\mathrm{H}}^{\mathrm{MCDTA}} \\
\mathrm{M}^{-1} \mathrm{~s}^{-1}\end{array}$ & $\mathrm{pH}$ range & $\begin{array}{l}k_{1}{ }^{\mathrm{MCDTA}} \\
\mathrm{s}^{-1}\end{array}$ & $\begin{array}{l}k_{\mathbf{2}} \mathrm{MCDTA} \\
\mathrm{s}^{-1}\end{array}$ & pH range \\
\hline $\mathbf{M g}$ & 25.0 & $\begin{array}{l}7.7 \times 10^{-5} \\
\left(5.2 \times 10^{-4}\right)^{b} \\
(0)^{c}\end{array}$ & $\begin{array}{c}7.1 \times 10^{4} \\
\left(3.8 \times 10^{4}\right)^{b} \\
\left(6.33 \times 10^{4}\right)^{c}\end{array}$ & $\begin{array}{l}7.7-8.4 \\
(8.5-9.2)^{b} \\
(5.5-7.6)^{c}\end{array}$ & $2.4 \times 10^{-5}$ & $5.3 \times 10^{-5}$ & $10.4-11.0$ \\
\hline & $\begin{array}{l}32.3 \\
39.5\end{array}$ & $\begin{array}{l}1.2 \times 10^{-4} \\
1.9 \times 10^{-4}\end{array}$ & $\begin{array}{l}1.3 \times 10^{5} \\
2.4 \times 10^{5}\end{array}$ & $\begin{array}{l}7.6-8.6 \\
7.6-9.0\end{array}$ & $\begin{array}{l}3.6 \times 10^{-5} \\
5.7 \times 10^{-5}\end{array}$ & $\begin{array}{l}8.1 \times 10^{-5} \\
1.3 \times 10^{-4}\end{array}$ & $\begin{array}{l}11.0-11.3 \\
10.8-11.1\end{array}$ \\
\hline \multirow[t]{3}{*}{$\mathrm{Ca}$} & & & & & & & \\
\hline & 25.0 & $\begin{array}{l}3.1 \times 10^{-5} \\
\left(2.1 \times 10^{-4}\right)^{b} \\
(0)^{c}\end{array}$ & $\begin{array}{l}5.4 \times 10^{5} \\
\left(4.2 \times 10^{5}\right)^{b} \\
\left(4.14 \times 10^{5}\right)^{c}\end{array}$ & $\begin{array}{c}7.6-11.4 \\
(8.5-10.5)^{b} \\
(5.5-7.6)^{c}\end{array}$ & & & \\
\hline & $\begin{array}{l}32.4 \\
39.5\end{array}$ & $\begin{array}{l}7.1 \times 10^{-5} \\
1.1 \times 10^{-4}\end{array}$ & $\begin{array}{l}1.0 \times 10^{5} \\
1.7 \times 10^{5}\end{array}$ & $\begin{array}{l}8.2-11.1 \\
8.0-10.7\end{array}$ & & & \\
\hline \multicolumn{8}{|l|}{$\mathbf{S r}$} \\
\hline & $\begin{array}{l}16.4 \\
25.0\end{array}$ & $\begin{array}{l}3.9 \times 10^{-8} \\
8.0 \times 10^{-8} \\
\left(1.4 \times 10^{-2}\right)^{b} \\
\left(3.0 \times 10^{-2}\right)^{c}\end{array}$ & $\begin{array}{l}3.5 \times 10^{6} \\
6.4 \times 10^{6} \\
\left(6.7 \times 10^{6}\right)^{b} \\
\left(6.06 \times 10^{6}\right)^{c}\end{array}$ & $\begin{array}{c}8.4-8.8 \\
8.3-8.9 \\
(8.5-9.2)^{b} \\
(5.5-7.6)^{c}\end{array}$ & $\begin{array}{l}2.2 \times 10^{-8} \\
4.2 \times 10^{-8}\end{array}$ & $\begin{array}{l}1.7 \times 10^{-3} \\
3.8 \times 10^{-3}\end{array}$ & $\begin{array}{l}10.4-11.0 \\
10.5-10.9\end{array}$ \\
\hline & 31.4 & $1.5 \times 10^{-2}$ & $8.4 \times 10^{8}$ & $8.2-8.9$ & $7.9 \times 10^{-8}$ & $6.6 \times 10^{-3}$ & $10.5-11.0$ \\
\hline \multirow[t]{2}{*}{ La } & 25.0 & $\begin{array}{l}2.1 \\
(0)^{d} \\
(0)^{e}\end{array}$ & $\begin{array}{l}2.8 \times 10^{2} \\
\left(1.66 \times 10^{2}\right)^{d} \\
\left(2.34 \times 10^{2}\right)^{e}\end{array}$ & $\begin{array}{c}5.7-7.7 \\
(3.9-5.3)^{d} \\
(4.6-5.5)^{e}\end{array}$ & $(0)$ & $2.1 \times 10^{-4}$ & \\
\hline & $\begin{array}{l}32.0 \\
39.5 \\
\end{array}$ & $\begin{array}{l}3.8 \times 10^{-4} \\
7.9 \times 10^{-4} \\
\end{array}$ & $\begin{array}{l}4.1 \times 10^{2} \\
7.5 \times 10^{2} \\
\end{array}$ & $\begin{array}{l}5.5-7.7 \\
5.5-7.6 \\
\end{array}$ & $\begin{array}{l}(0) \\
(0)\end{array}$ & $\begin{array}{l}3.8 \times 10^{-4} \\
7.8 \times 10^{-4}\end{array}$ & \\
\hline
\end{tabular}

${ }^{a} \mu=0.5\left(\mathrm{CsNO}_{3}\right)$ for $\mathrm{M}=\mathrm{Mg}, \mathrm{Ca}$, and Sr; $\mu=0.1\left(\mathrm{CsNO}_{3}\right)$ for $\mathrm{M}=\mathrm{La} .{ }^{b}$ Ref. $1 ; \mu=0.5\left(\mathrm{NH}_{4} \mathrm{NO}_{3}\right) .{ }^{c} \mathrm{Ref}{ }^{15}$; $\mu=0.5$ (Na-acetate). ${ }^{d}$ Ref. $4 ; \mu=0.1\left(\mathrm{NaClO}_{4}\right) .{ }^{e}$ Ref. $3 ; \mu=0.1\left(\mathrm{NaClO}_{4}\right)$.

Table 4 shows the resolved rate constants calculated in accordance with the procedure described in the previous paragraphs as well as the corresponding rate constants from the literature. Satisfactory agreement is found for $k_{\mathrm{H}}{ }^{\mathrm{MCDTA}}$ even in the event that the $\mathrm{pH}$ range in the present investigation is not the same as that in the cited studies. $k_{1}{ }^{\text {MCDTA }}$ and $k_{2}{ }^{\text {MCDTA }}$ cannot be calculated in the case of CaCDTA since no deviation from eqn. (7) is observed in the investigated $\mathrm{pH}$ range. The dissociation reaction of CaCDTA, on the other hand, may well follow mechanism (8). It is a possibility that the deviation from eqn. (7) appears at a higher value of $\mathrm{pH}$ which would indicate that $k_{21}$ is larger than $k_{28}$ but relatively small compared with $k_{24}\left[\mathrm{H}^{+}\right]$. It is remarkable that $k^{\text {MCDTA }}$ for the exchange reactions between the CDTA complexes of the alkaline earth ions and metal ions is considerably larger than the corresponding rate constants obtained in the present investigation (cf. Jensen and Larsen ${ }^{1}$ ). This fact may be related to a dependence on the metal ion concentration similar to the dependence on $\left[\mathrm{H}^{+}\right]$in mechanism (8) (cf. Nyssen and Margerum "). Another explanation for the difference between the values obtained for $k_{M}$ CDTA in the present work and the work by Jensen and Larsen ${ }^{1}$ may involve the $\mathrm{NH}_{4}+/ \mathrm{NH}_{3}$ buffer used in that investigation in a manner similar to an effect observed with ammonium acetate in a study on isotopic $\mathrm{Ce}$ (III)exchange in $\mathrm{Ce}(\mathrm{III})$ polyaminocarboxylic acid chelates by Balcombe and Wiseall. ${ }^{12}$

The direct dissociation of the CDTA complexes according to mechanism (8) proceeds along reaction path $1 \rightarrow \mathbf{2} \rightarrow \mathbf{3}$. A necessary condition for this dissociation mechanism is that the rate of the reverse reaction be slower than the diffusion controlled rate of the reaction between two ions, i.e., about $10^{10} \mathrm{M}^{-1} \mathrm{~s}^{-1}$ ( $c f$. Caldin ${ }^{13}$ ). Furthermore, the rate of the reverse reaction where the rate determining step $(r d s)$ is $2 \rightarrow 1$ must be slower than the rate of formation for the water exchange mechanism of the aquo metal ion. ${ }^{14}$

Eqn. (13) shows how the rate constant Acta Chem. Scand. A 28 (1974) No. 6 
Table 5. Comparison of calculated rate constants for the formation of MCDTA from $\mathbf{M}^{n+}$ and $\mathrm{CDTA}^{4-}$ at $25^{\circ} \mathrm{C}$ with values predicted from the rate constants of water exchange.

\begin{tabular}{|c|c|c|c|}
\hline $\mathbf{M}$ & $\begin{array}{l}k_{\mathrm{M}}^{\mathrm{CDTA}} \\
\mathrm{M}^{-1} \mathbf{S}^{-1}\end{array}$ & $\begin{array}{l}k_{\mathrm{M}^{-}}-\mathrm{H}_{2} \mathrm{O} \\
\mathrm{s}^{-1}\end{array}$ & 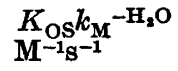 \\
\hline
\end{tabular}

\begin{tabular}{lccc}
\hline $\mathrm{Mg}$ & $2.5 \times 10^{6}$ & $\left(1.4 \times 10^{5}\right)^{b}$ & $7.0 \times 10^{6}$ \\
$\mathrm{Ca}$ & $\left(3.9 \times 10^{8}\right)^{a}$ & $\left(3.0 \times 10^{8}\right)^{c}$ & $1.5 \times 10^{10}$ \\
$\mathrm{Sr}$ & $1.3 \times 10^{8}$ & $\left(3.5 \times 10^{8}\right)^{c}$ & $1.8 \times 10^{10}$ \\
$\mathrm{La}$ & & $\left(5.2 \times 10^{8}\right)^{d}$ & $>2.6 \times 10^{10}$ \\
\hline
\end{tabular}

$a k_{1}$ CaCDTA is assumed equal to $k^{\text {CaCDTA. } b, c, d}$ Ref. 16, 17, and 18, respectively.

$k_{M}$ CDTA for the formation of $\operatorname{MCDTA}^{(4-n)-~ f r o m ~}$ $M^{n+}$ and CDTA ${ }^{4}$ has been calculated from $k_{1}{ }^{\text {MCDTA }}$ and the stability constant for the corresponding complex MCDTA ${ }^{(4-n)-}$.

$k_{\mathrm{M}}{ }^{\mathrm{CDTA}}=k_{1}{ }^{\mathrm{MCDTA}} K_{\mathrm{MCDTA}}$

Table 5 shows values for $k_{\mathrm{M}}$ CDTA calculated from eqn. (13) as well as the values predicted from the water exchange rate of the outer sphere complex. $K_{O S}$ is the outer-sphere association constant; a value of $50 \mathrm{M}^{-1}$ has been used for the $2+$ metal and the $4-$ ligand ${ }^{15}$ whereas a value larger than $50 M^{-1}$ has been used for the $3+$ metal ion $\left(\mathrm{La}^{3+}\right.$ ) and the $4-$ ligand (cf. Table 5). It is seen that the values of $K_{\mathrm{OS}} k_{\mathrm{M}}{ }^{-\mathrm{H}_{2} \mathrm{O}}$ are larger than the values of $k_{M}$ CDTA. $k_{1}$ LaCDTA is found to be negligible (cf. Table 4). A calcula. tion by means of eqn. (13) using the diffusion controlled value, $k_{\mathrm{L}, \mathrm{C}}$ CDTA $=10^{10} \mathrm{M}^{-1} \mathrm{~s}^{-1}$, yields a $k_{1}$ IaCDTA $\leq 10^{-7} \mathrm{~s}^{-1}$. The values of $k_{1}$ MCDTA, as calculated in the preceding section, are therefore consistent with mechanism (8).

Activation parameters. The rds in mechanism (8) is assumed to be $1 \rightarrow 2$. Accordingly, the activation parameters for $k_{1}$ MCDTA and $k_{2}$ MCDTA must be the same. The dependence of the resolved rate constants on temperature is shown in Table 4. Arrhenius plots of $\log k$ versus $T^{-1}$ show satisfactory linearity, even in the case of $k=k_{2}{ }^{\mathrm{MgCDTA}}$ or $k_{2}{ }^{\mathrm{SrCDTA}}$ where $k$ is determined with some uncertainty because of the rather large values of $k_{\mathrm{d}} \cdot \Delta H \neq, \Delta S \neq$, and $\Delta G \neq$ are calculated using the Arrhenius plots ( $c f$. Table 6). Table 6 indicates that the requirements for identical activation parameters for $k_{1}{ }^{\text {MCDTA }}$ and $k_{2}$ MCDTA is fulfilled. The value of $\Delta G \neq$ and the pronounced negative value of $\Delta S \neq$ for $k^{\text {CaCDTA }}$
Table 6. Activation parameters for the resolved rate constants; $25^{\circ} \mathrm{C}$.

\begin{tabular}{llll}
\hline $\mathrm{M}$ & $\begin{array}{l}\Delta H \neq \\
\mathrm{kJ} \mathrm{mol}\end{array}$ & $\begin{array}{l}\Delta S \neq \\
\mathrm{J}(\mathrm{deg} \mathrm{mol})^{-1}\end{array}$ & $\begin{array}{c}\Delta G \neq \\
\mathrm{kJ} \mathrm{mol}-1\end{array}$ \\
\hline
\end{tabular}

\begin{tabular}{llcc}
$\mathrm{Mg}$ & & & \\
$k_{1}$ & 44 & -187 & 100 \\
$k_{2}$ & 46 & -172 & 97 \\
$k_{\mathrm{H}}$ & 66 & 61 & 46 \\
$\mathrm{Ca}$ & & & \\
$k^{a}$ & 72 & -92 & 99 \\
$k_{\mathrm{H}}$ & 62 & 72 & 41 \\
$\mathrm{Sr}$ & & & \\
$k_{1}$ & 61 & -88 & 87 \\
$k_{2}$ & 65 & -74 & 87 \\
$k_{\mathrm{H}}$ & 41 & 24 & 34 \\
$\mathrm{La}$ & & & \\
$k_{2}$ & 83 & -45 & 96 \\
$k_{\mathrm{H}}$ & 53 & -20 & 59 \\
& $(54)^{b}$ & $(-22)^{b}$ & $(61)^{b}$ \\
\hline
\end{tabular}

${ }^{a} k_{\text {CaCDTA. }} b, c$ Ref. 4 and 3, respectively.

resemble the parameters obtained for the corresponding reactions with magnesium, strontium, and lanthanum complexes. Mechanism (8) would therefore appear to account for all the reactions examined in a very convincing manner.

It is seen from Table 6 that all the reactions related to (8) show a pronounced negative entropy of activation which may be related to a solvation of the transition state. Solvation could come about if step $1 \rightarrow 2$ in mechanism (8) involves the breaking of a metal ion chelate bond followed by the solvation of the free coordination site of the metal ion. Such a solvation gives rise to a change of the solvation of the complex as a whole.

The free energies of activation are remarkably constant for step $1 \rightarrow 2$ for the MCDTA complexes investigated. Nyssen and Margerum have proposed that step $1 \rightarrow 2$ is a slow distortion of the complex which is consistent with an angular displacement instead of a linear displacement in preparation for opening the chelate rings ( $c f$. Margerum ${ }^{19}$ ). Assuming the angular displacement theory, the free energy of activation is related to the rotational barriers of the chelate which again is related to the type of ligand. Furthermore, Day and Reilley ${ }^{21}$ have

Acta Chem. Scand. A 28 (1974) No. 6 
used an NMR technique in their studies on these complexes and suggest that the relatively long lifetime of the $N-M$ bond is correlated with the steric hindrance caused by this ligand. This hindrance would make the support of a water molecule in the bond breaking impossible. The constant free energy of activation may then be rendered comprehensible in terms of these theories.

The rate constant of dissociation $k_{\mathrm{d}}$ is given by eqn. (7) at low values of $\mathrm{pH}$. $k_{\mathrm{H}}$ MCDTA has been accurately determined in the studies by Margerum et al. ${ }^{20}$ and Nyssen and Margerum. ${ }^{4}$ The activation parameters found in the present investigation for this pathway of the dissociation reaction of LaCDTA agree with the values found by Nyssen and Margerum, ${ }^{4}$ whereas Brücher and Szarvas ${ }^{21}$ find different values for $\Delta H \neq$ and $\Delta S \neq$, but the same value for $\Delta G \neq$.

It has been found that $k_{\mathrm{H}}$ MCDTA represents an $r d s$ which involves a proton attack on one of the nitrogen atoms. This attack results in an intermediate with the metal ion outside the coordination cage of the ligand (cf. Margerum et al. ${ }^{20}$ and Nyssen and Margerum ${ }^{4}$ ). Mechanism (8) has accordingly to be extended to that shown in (14) which is valid at both the low and high values of $\mathrm{pH}$ used in this work. M*HCDTA in mechanism (14) has been observed by Nyssen

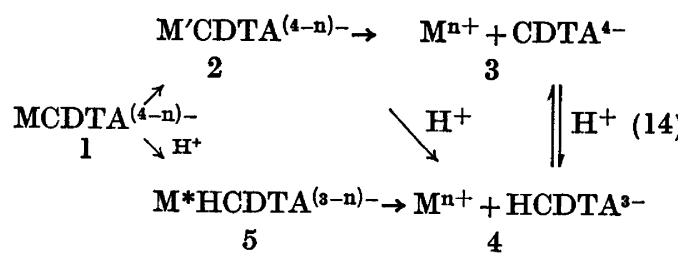

and Margerum ${ }^{4}$ in their study on the rate of formation of LaCDTA. Studies ${ }^{1}$ on the rate of dissociation of this type of complexes all show a similar $\left[\mathrm{H}^{+}\right]$profile for these reactions with $\mathrm{M}=\mathrm{Mg}$, $\mathrm{Sr}$, or $\mathrm{Ba}$; the present study shows this same $\left[\mathrm{H}^{+}\right]$profile for $\mathrm{M}=\mathrm{Mg}, \mathrm{Sr}$, or La.

The dissociation reaction for these MCDTA complexes is therefore assumed to follow mechanism (14) in the investigated $\mathrm{pH}$ range and for $\mathrm{M}=\mathrm{Mg}, \mathrm{Ca}, \mathrm{Sr}, \mathrm{Ba}$, or $\mathrm{La}$ (cf. the preceding discussion). The $r d s$ are $1 \rightarrow 2$ and $1 \rightarrow 5$ for the spontaneous and the $\mathrm{H}^{+}$activated dissociation, respectively. The $r d s \quad 1 \rightarrow 5$ dominates at low values of $\mathrm{pH}$ and $r d s \quad 1 \rightarrow 2$ dominates at relatively high values of $\mathrm{pH}$.
Acknowledgements. The authors wish to thank Professor K. H. Pearson, Cleveland State University, Cleveland, Ohio, U.S.A., for a sample of optically active $\mathrm{H}_{4} \mathrm{CDTA}$, Dr. $\mathrm{O}$. Farver of this institution for fruitful and instructive discussions and Dr. D. Bennett of this institution for linguistic help.

\section{REFERENCES}

1. Jensen, A. and Larsen, N. R. Acta Chem. Scand. 27 (1973) 1838.

2. a. Glentworth, P., Wiseall, B., Wright, C. L. and Mahmood, A. J. J. Inorg. Nucl. Chem. 30 (1968) 967; b. Glentworth, P. and Newton, D. A. J. Inorg. Nucl. Chem. 33 (1971) 1701.

3. Brücher, E. and Szarvas, P. Acta Chim. (Budapest) 67 (1971) 449.

4. Nyssen, G. A. and Margerum, D. W. Inorg. Chem. 9 (1970) 1814.

5. Dwyer, F. P. and Garvan, F. L. J. Amer. Chem. Soc. 83 (1961) 2610.

6. Reinbold, P. E. and Pearson, K. H. Inorg. Chem. 9 (1970) 2325.

7. Carr, J. D. and Swartzfager, D. G. Anal. Chem. 43 (1971) 1520.

8. Carr, J. D. and Baker, D. R. Inorg. Chem. 10 (1971) 2249.

9. Margerum, D. W. Rec. Chem. Progr. 24 (1963) 237.

10. Anderegg, G. Helv. Chim. Acta 46 (1963) 1833.

11. Basolo, F. and Pearson, R. G. Mechanisms of Inorganic Reactions, 2. Ed., Wiley, New York 1967, p. 218.

12. Balcombe, C. I. and Wiseall, B. J. Inorg. Nucl. Chem. 35 (1973) 2859.

13. Caldin, E. F. Fast Reactions in Solution, Blackwell, Oxford 1964, p. 279.

14. Eigen, M. and Wilkins, R. G. Mechanisms of Inorganic Reactions, American Chemical Society, Washington, D. C. 1965 , p. 55.

15. Pausch, J. B. and Margerum, D. W. Anal. Chem. 41 (1969) 226.

16. Petrucci, S. and Atkinson, G.J. Phys. Chem. 70 (1966) 3122.

17. Eigen, M. and Maass, G. Z. Phys. Chem. (Frankfurt am Main) 49 (1966) 163.

18. Purdie, N. and Vincent, C. A. Trans. Faraday Soc. 63 (1967) 2745.

19. Ref. 14, p. 75.

20. Margerum, D. W., Menardi, P. J. and Janes, D. L. Inorg. Chem. 6 (1967) 283.

21. Day, R. J. and Reilley, C. N. Anal. Chem. 37 (1965) 1326.

Received February 14, 1974.

Acta Chem. Scand. A 28 (1974) No. 6 